\title{
Bastidores da reportagem sobre assédios sexuais que gerou o movimento \#MeToo: reflexões sobre o jornalismo com perspectiva de gênero
}

\author{
Behind the scenes of the sexual harassment report that spawned \\ the \#MeToo movement: reflections on the journalism from a gender \\ perspective
}

\section{Bastidores del reportaje sobre acosos sexuales que generó el movimiento \#MeToo: reflexiones sobre el periodismo desde una perspectiva de género}

Lais de Mello Rocio ${ }^{1, a}$

laismrocio@gmail.com | https://orcid.org/0000-0002-8729-4165

Rafael Paes Henriques ${ }^{1, b}$

rafaelpaesh@gmail.com | https://orcid.org/oooo-0002-1812-5886

Gabriela Santos Alves ${ }^{1, c}$

gabriela.alves@ufes.br | https://orcid.org/0000-0001-5243-7499

${ }^{1}$ Universidade Federal do Espírito Santo, Programa de Pós-graduação em Comunicação e Territorialidades. Vitória,
ES, Brasil.

a Graduação em Jornalismo pela Universidade Federal do Espírito Santo.

b Doutorado em Filosofia pela Universidade Federal do Rio de Janeiro.

c Doutorado em Comunicação e Cultura pela Universidade Federal do Rio de Janeiro.

\section{RESUMO}

Este artigo realiza aproximações conceituais da epistemologia feminista, considerando a teoria crítica do jornalismo como forma de conhecimento social, com o objetivo de discutir a importância da perspectiva de gênero em reportagens sobre a cultura do estupro. Como corpus de análise, selecionamos o livro-reportagem Ela Disse: os bastidores da reportagem que impulsionou o \#MeToo, que retrata a produção das notícias do New York Times sobre abusos sexuais contra atrizes e funcionárias da indústria cinematográfica de Hollywood. Sistematizamos as teorias levantadas para apontar parâmetros do jornalismo com perspectiva feminista. Definimos, como aspectos e categorias de análise das reportagens, a contextualização, os desafios e estratégias de apuração da violência de gênero e cultura do estupro como formas de organização social e questões de saúde pública. Como resultados, reforçamos a necessidade da abordagem feminista no jornalismo para gerar a reflexão pela sociedade, o enfrentamento da violência e da desigualdade de gênero.

Palavras-chave: Estupro; Feminismo; Jornalismo; Violência contra mulheres; Perspectiva de gênero. 


\section{ABSTRACT}

This article deals with conceptual approaches of feminist epistemology, bearing in mind the critical theory of journalism as a form of social knowledge, aiming to discuss the importance of the gender perspective in reports on the rape culture. As a corpus of analysis, we selected a book written by two investigative reporters, She said: breaking the sexual harassment story that helped ignite a movement, which portrays the New York Times production of news regarding sexual abuse and harassment of actresses and women employees by their bosses in Hollywood film industry. We have systematized the theories raised to point out parameters of journalism with a feminist perspective. We defined, as aspects and categories of analysis of the reports, the contextualization, challenges and strategies for investigating gender violence and rape culture as forms of social organization and public health issues. As a result of the study, we reinforce the need for a feminist approach in journalism to generate a reflection on these problems by society, and to confront the gender violence and inequality.

Keywords: Rape; Feminism; Journalism; Violence against women; Gender perspective.

\section{RESUMEN}

Este artículo realiza aproximaciones conceptuales de la epistemología feminista, teniendo em cuenta la teoría crítica del periodismo como forma de conocimiento social, con el objetivo de discutir la importancia de la perspectiva de género en los reportajes sobre la cultura de la violación. Como corpus de análisis, seleccionamos el libro-reportaje Ela disse: os bastidores da reportagem que impulsionou o \#MeToo [Ella ha dicho: los bastidores del reportaje que ha impulsionado el movimiento \#MeToo], que retrata la producción de noticias del New York Times sobre acosos sexuales sufridos por actrices y empleadas de la industria cinematográfica de Hollywood. Hemos sistematizado las teorías planteadas para señalar parámetros del periodismo con una perspectiva feminista. Definimos, como aspectos y categorías de análisis de los reportajes, la contextualización, los desafíos y algunas estrategias de investigación de la violencia de género y la cultura de la violación como formas de organización social y cuestiones de salud pública. Como resultado, reforzamos la necesidad de un enfoque feminista en el periodismo para generar reflexión por la sociedad, y más el enfrentamiento de la violencia y de la desigualdad de género.

Palabras clave: Violación; Feminismo; Periodismo; La violencia contra las mujeres; Perspectiva de género.

Este artigo compõe o dossiê Feminismos: perspectivas em comunicação e informação em saúde, parte 1.



Licença CC BY-NC atribuição não comercial. Com essa licença é permitido acessar, baixar (download), copiar, imprimir, compartilhar, reutilizar e distribuir os artigos, desde que para uso não comercial e com a citação da fonte, conferindo os devidos créditos de autoria e menção à Reciis. Nesses casos, nenhuma permissão é necessária por parte dos autores ou dos editores. 


\section{INTRODUÇÃO}

O presente artigo dedica-se a refletir sobre os conceitos da epistemologia feminista e suas aproximações teóricas com a teoria crítica do jornalismo como forma de conhecimento social, com o objetivo de identificar e discutir parâmetros para a construção da perspectiva de gênero na reportagem. Por meio da discussão de conceitos como objetividade, subjetividade e contextualização, construímos diálogos conceituais e critérios práticos que podem gerar novas formas de representação feminina nos conteúdos noticiosos. Pretende-se compreender, à luz da ciência feminista, de que forma o jornalismo pode ser capaz de romper com perspectivas machistas e excludentes, que anulam e/ou inferiorizam a experiência feminina em seus relatos. Assim, nos dedicamos a caracterizar caminhos para compreensões de mundo que expressam a multiplicidade e diversidade de vozes e vivências de mulheres. E isso incluis suas questões, valores e crenças em uma sociedade marcada pela violência e desigualdade de gênero, em que prevalece o poder masculino.

Ao investigar possibilidades de enfrentamento da violência de gênero pelo jornalismo, discutimos a maneira como a notícia retrata, tradicionalmente, os casos de assédio e violência sexual contra mulheres. Debatemos as tradições da dominação masculina em toda a estrutura social e nos modelos de produção de conhecimento. Após essa contextualização e problematização inicial, iremos alcançar a identificação e discussão das mudanças, desafios e esforços a serem tomados na produção jornalística, de modo a gerar reflexão, esclarecimento e enfrentamento da violência de gênero, ao retratar casos de violência sexual a partir de abordagens feministas.

A partir dessa reflexão teórica, voltada para a discussão sobre a violência de gênero e a cultura do estupro nas notícias, realizamos a análise do livro-reportagem Ela disse: os bastidores da reportagem que impulsionou o \#MeToo (KANTOR; TWOHEY, 2019), que narra detalhes da investigação jornalística sobre assédios sexuais contra atrizes e funcionárias da indústria cinematográfica de Hollywood, publicada no New York Times (NYT) em 2017 por Jodi Kantor e Megan Twohey, conquistando o Prêmio Pulitzer 2018, na categoria 'serviço público'.

Com a análise do livro, o estudo propõe construir uma compreensão completa e representativa dos caminhos percorridos pela cobertura jornalística de profundidade sobre a violência sexual contra mulheres. Percebemos, nos relatos narrados no livro, a motivação das repórteres em investigar e contextualizar a violência de gênero e experiência feminina de forma sensível e humanizada. Entendendo que essa cobertura se contrapõe aos discursos jornalísticos tradicionais, que costumam naturalizar ou justificar a violência masculina, trazemos a análise e discussão do livro-reportagem de Kantor e Twohey (2019) com o objetivo de revelar, concretamente, de que maneiras essa nova visão feminista do fazer jornalístico opera e pode operar, inclusive servindo de referência para demais coberturas, e para a efetiva institucionalização de um novo protocolo da perspectiva de gênero na imprensa.

Ao olharmos para a produção do NYT, que gerou repercussão no debate público, na investigação e punição dos acusados, ao alavancar denúncias que fizeram parte do \#MeToo - campanha mundial que fez circular denúncias de estupro nas redes sociais -, torna-se possível compreender questões representativas desse tipo de cobertura com viés feminista e revolucionário. A partir da divulgação de denúncias inéditas de diversas mulheres, que até então mantinham sigilo sobre os abusos inclusive pela indústria de acordos de silêncio das vítimas, descoberta pelo NYT, a reportagem e a amplificação de denúncias com a hashtag culminaram na condenação do produtor de Hollywood, Harvey Weinstein, a 23 anos de prisão pelos abusos cometidos, assim como levaram à exposição e demissão de diversos homens famosos do meio profissional e do poder público dos EUA.

A mobilização global e histórica de quebra do silêncio de mulheres sobre os abusos sexuais levou à incorporação desses movimentos em diversos países. No Brasil, a campanha \#MeTooBrasil foi criada 
em 2020, inspirada no \#MeToo originado nos Estados Unidos, mas com particularidades e finalidades específicas. Assim como ocorreu em Hollywood a partir da série de assédios na indústria cultural e cinematográfica, principalmente por Harvey Weinstein, a campanha brasileira surgiu a partir de revelações de mulheres nas redes sociais sobre abusos cometidos pelo produtor de cinema e curador de festivais, Gustavo Beck. Nesse contexto, o caso foi revelado sistematicamente pelo site The Intercept Brasil, na reportagem 'As mordidas foram profundas': Curador brasileiro de festivais internacionais de cinema é acusado de abuso sexual por 16 mulheres' (FELIZARDO; ALVES, 2020), publicada em agosto de 2020. Assim, o papel revelador da reportagem se deu tal como a atuação do New York Times nos EUA, atribuindo ao jornalismo a função fundamental de atuar como mediador das denúncias, fomentar a quebra do silêncio entre as mulheres e o debate sobre a violência sexual. Com isso, o \#MeTooBrasil foi criado no mês seguinte por um grupo de advogadas e juristas, inclusive a promotora de justiça Gabriela Manssur, que atuou na força tarefa do Ministério Público na investigação do caso João do Deus, líder espiritual brasileiro condenado por abusar sexualmente de mais de 300 vítimas em 2018, com revelações inéditas em reportagens feitas pela Rede Globo.

A campanha brasileira surge, segundo declarações das fundadoras em entrevistas a jornais, para dar visibilidade às denúncias e amplificar as vozes das mulheres. E mais do que apenas fomentar o debate nas redes sociais pela hashtag, elas dizem se dedicar ao apoio psicológico e jurídico das vítimas. O principal diferencial desse movimento, no Brasil, foi um portal digital criado para acolher denúncias das mulheres, as quais as advogadas dizem encaminhar para a abertura de investigações pelas autoridades responsáveis. O movimento reúne cerca de 3.600 voluntárias, em todo o país, para prestar esse atendimento jurídico (FREIRE, 2020).

Assim, a partir do livro analisado, nos dedicamos a identificar como a cobertura do New York Times incorpora as noções da perspectiva de gênero. Para a construção dessa metodologia de análise, nos baseamos na análise de conteúdo estruturada por Bardin (2007). A partir da realização da leitura flutuante do livro, realizamos a definição de critérios de interpretação de acordo com a análise temática, que identifica os “"núcleos de sentido’ que compõem a comunicação e cuja presença, ou frequência de aparição, podem significar alguma coisa para o objetivo analítico escolhido" (BARDIN, 2007, p. 105). Dessa maneira, realizamos o recorte do material estudado com base nos principais temas que visualizamos como norteadores nesse tipo de abordagem jornalística. Elencamos as principais características e desafios que parecem envolver esse tipo de reportagem, definindo categorias de análise que guiam a seleção e interpretação dos relatos a partir dos seguintes temas 1) contextualização da violência de gênero e cultura do estupro como formas de organização social; 2) sensibilidade e subjetividade ao retratar a experiência feminina; 3) desafios de apuração e checagem do assédio sexual; 4) perspectivas feministas de transformação social a partir das notícias, ao proporem e mobilizarem mudanças na ordem social da violência contra mulheres.

A construção desses critérios se justifica pelo fato de a contextualização jornalística ser apresentada, a partir da nossa revisão teórica, como processo fundamental para gerar entendimento integrado e estrutural sobre a violência de gênero. Isso se faz necessário para que esses casos se desloquem de uma visão reduzida ao ponto de vista pontual e criminal, materializando-se na reportagem do NYT pela busca explícita e constante por um "padrão de comportamento predatório" (KANTOR; TWOHEY, 2019, p. 81) de "homens poderosos" (KANTOR; TWOHEY, 2019, p. 62) ao longo da investigação. Tal visão contextual envolve a inclusão de aspectos subjetivos, que compõem a construção simbólica por trás dessa violência sexual, representando diversos sentidos para quem a comete e para quem é vítima, tal como se percebe em passagens do livro que ressaltam emoções, dores, memórias, anseios e demais elementos desse tipo. Por isso, a subjetividade também se torna categoria principal de análise neste estudo. 
Os desafios de apuração jornalística são também definidos como critério de análise por sua recorrência e materialidade no livro analisado, e por serem significativos para o entendimento das questões que ameaçam a própria cobertura jornalística que questiona essa dominação masculina, especialmente quando a reportagem é realizada por mulheres jornalistas. Por fim, a categoria temática da transformação social, com perspectivas feministas, justifica-se por sintetizar as maneiras de enfrentamento da desigualdade de gênero e mudanças da estrutura de poder masculino, que também compõem fundamentalmente o nosso debate teórico e assumem papel de protagonismo no livro do NYT, ao passo que este percorre, ao longo dos relatos, o caráter revolucionário do fomento ao \#MeToo e as mobilizações das mulheres vítimas de assédios. Ao mesmo tempo, ele questiona o alcance dessa mudança, ao narrar legislações e estruturas de poder que permanecem intatas dando respaldo à violência masculina.

Com esta sistematização do estudo empírico, acreditamos alcançar um discernimento voltado para os sentidos e efeitos que a cultura do estupro gera para a saúde mental das mulheres, com as construções simbólicas do medo, culpabilização e silenciamento gerado a partir desses atos, bem como se torna possível observar seus impactos na saúde pública. À medida que as visões feministas nos levam a politizar o debate em torno desses abusos masculinos - até então tidos como íntimos e reclusos à subjetividade da mulher - torna-se possível debater o enfrentamento da violência contra mulheres pelo viés de responsabilidade social representado nessa questão.

Ao mesmo tempo, pontuamos como possíveis limitações deste estudo a complexidade das dificuldades de apuração jornalística do abuso sexual, o que torna desafiadora a replicação dos mesmos padrões presentes em uma cobertura tão profunda e completa quanto à do NYT, que possuía aparato jurídico, financeiro e político. Dessa forma, enxergamos a possibilidade da abordagem feminista na imprensa como difícil de ser acolhida e legitimada, considerando a consistência e legitimidade da tradição masculinista que ainda rege a estrutura organizacional e as rotinas produtivas dos jornais.

\section{CULTURA DO ESTUPRO: ORIGENS E IMPLICAÇÕES NO JORNALISMO}

Entendemos a cultura do estupro, que compõe o sistema de desigualdade de gênero, enquanto um dos pilares de organização das sociedades ao longo da História. Como explicita Saffioti (1994), não existe nenhuma sociedade sem uma organização de gênero, e essa diferenciação vigente na história humana se torna negativa na medida em que "se transforma em hierarquias, seja na direção de inferiorizar a mulher, como acontece em todas as sociedades em maior ou menor grau, seja na direção oposta” (SAFFIOTI, 1994, p. 461). Esse sistema gera a perpetuação do poder exercido por homens sobre as escolhas, a vida e realizações de mulheres, e do próprio corpo feminino. Como mostra Bandeira (2019), "as diferentes manifestações da violência de gênero são maneiras de estabelecer uma relação de submissão ou de poder, implicando sempre situações de medo, isolamento, dependência e intimidação para a mulher” (p. 304).

Esse entendimento da violência de gênero surge como uma maneira de classificar o comportamento da dominação masculina sobre as mulheres, como pano de fundo das agressões e abusos cotidianos. Essa forma de interpretar a violência masculina contra mulheres surge como uma demanda feminista em busca das origens e do enfrentamento desses crimes, cujo pensamento teórico atua "destacando a natureza das relações de poder estabelecidas entre homens e mulheres, nas conjugalidades e famílias” (BANDEIRA, 2019, p. 299).

Dessa maneira, torna-se fundamental indicar e caracterizar a "onipresença" (p. 445) dessa violência, como descreve Saffioti (1994), que se perpetua tanto no plano das ideias, enquanto violência simbólica, quanto no plano material enquanto violência física e sexual. Entendemos que a desigualdade de gênero não representa somente "um conjunto mais ou menos sistemático de ideias, mas também, e fundamentalmente, de estruturas de poder" (p. 444). Isso nos leva a enxergar, portanto, "a violência enquanto modalidade 
material de controle social e da repressão exercida através das formas 'ideacionais' de socialização" (SAFFIOTI, 1994, p. 445).

Nesse mesmo sentido, Bandeira (2019) define essa problemática como sendo um "fenômeno social persistente, multiforme e articulado por facetas psicológica, moral e física” (p. 304). Portanto, não seria genérico afirmar que todas as mulheres convivem com a violência masculina, em diferentes medidas e formas de expressão, desde as convenções sociais que impõem e educam a maneira como mulheres devem viver, se comportar, se vestir e se expressar. Essa construção cultural naturaliza o comportamento masculino abusivo e agressivo como significado do que é 'ser homem'. Tal como mostra Saffioti (1994):

Potencialmente, todo homem é violento à medida que é incentivado, cotidianamente, a ser valente, a mostrar que é macho, masculinidade sendo sinônimo de transformação da agressividade em agressão. A mulher, ao contrário, é estimulada a suportar calada os maus-tratos a ela infligidos por seu companheiro, sobretudo quando este é um bom provedor das necessidades materiais da família (SAFFIOTI, 1994, p. 460).

Dessa maneira, esse modelo ideal de masculinidade é ensinado e construído no processo formador de homens desde a infância. Nessa direção, Bandeira (2019) caracteriza a violência contra mulheres como "apreendida no decorrer dos processos primários de socialização" (BANDEIRA, 2019, p. 304-305), e que permanece formando o comportamento social masculino ao longo da sociabilidade da vida adulta. Concluímos, então, que essa violência "não se caracteriza como patologia ou como desvio individual, mas sim como "permissão social" concedida aos homens na sociedade, em relação a qual estariam de acordo" (BANDEIRA, 2019, p. 304-305).

Em relação à legitimação social da violência contra mulheres, bell hooks (2019) argumenta que, como sintoma da sociedade patriarcal, "o sexismo alimenta, justifica e apoia a violência do homem contra a mulher" (HOOKS, 2019, p. 172). Considerando o patriarcado uma "estrutura de poder baseada tanto na ideologia quanto na violência”, percebemos que essas relações de poder envolvem inclusive a garantia de "direitos sexuais aos homens sobre as mulheres, praticamente sem restrição" (SAFFIOTI, 2004, p. 461).

Essa estrutura perpetua os direitos e relações patriarcais atribuídos aos homens sobre as mulheres tanto nos espaços públicos quanto privados, afetando desde as atividades sociais cotidianas até a dimensão íntima da sexualidade. Com isso, a partir da fundamentação das teorias feministas, acreditamos que o patriarcado "não se trata de uma relação privada, mas civil” (SAFFIOTI, 2004, p. 461). Reconhecemos a profunda ligação entre o público e o privado ao se tratar das relações de gênero. Assim, o direito patriarcal engloba, de forma quase orgânica, também a questão sexual, por meio do estabelecimento do "contrato sexual" como parte do "contrato social", que surge nas teorias clássicas da sociedade com a concepção de que "as relações sociais livres tomam uma forma contratual” (PATEMAN, 1993, p. 15). Como argumenta Pateman (1993), essa noção contratual das relações sociais esconde, intrinsecamente, um pacto que também é sexual: "o contrato cria o direito político dos homens sobre as mulheres -, e também sexual no sentido do estabelecimento de um acesso sistemático dos homens aos corpos das mulheres" (PATEMAN, 1993, p. 16-17).

É possível perceber a magnitude dessa violência ao olharmos para a realidade brasileira, em que mais da metade (59,1\%) da população havia presenciado alguma situação de violência e assédio contra mulheres no último ano, em seu bairro ou comunidade, de acordo com o Fórum Brasileiro de Segurança Pública (2019), de acordo com os dados coletados em 2019. Segundo o estudo, 16 milhões de mulheres brasileiras com mais de 16 anos relataram ter sofrido algum tipo de violência ou agressão no último ano, enquanto 22 milhões de mulheres reportaram ter sofrido algum tipo de assédio.

Como principal entendimento a partir da teoria feminista, reforçamos a necessidade de compreensão e discussão, fundamentalmente, da violência contra mulheres enquanto problema político, situando seu debate em uma questão pública e de responsabilidade social, que se desloca da dimensão íntima e privada 
pela qual foi historicamente reclusa (WILSHIRE, 1997). Com isso, olhamos especialmente para o impacto que isto representa no entendimento da cultura do estupro, a partir do ato feminista de politizar o íntimo. Esse pensamento leva à concepção e discussão das construções simbólicas geradas a partir da cultura do estupro, acarretando valores sociais e subjetivos que comprometem a experiência feminina. Para além das violências físicas, notamos os significados para os quais essa construção cultural orienta no que diz respeito à maneira como as mulheres compreendem a si mesmas e às suas realizações de vida. Entende-se, assim, que discutir a cultura do estupro significa, essencialmente, compreender e retratar crenças da subjetividade feminina que se articulam em meio a esses padrões de assédios.

\section{A COBERTURA JORNALÍSTICA SOBRE VIOLÊNCIA SEXUAL}

A partir desse olhar ampliado, torna-se necessário reconhecer que tais atos agressivos que aterrorizam mulheres não são tão pontuais ou isolados, tampouco tão imprevisíveis, como costumam ser caracterizados por impressões do senso comum e relatos noticiosos. Esse tipo de notícia perde de vista o real problema da cultura do estupro e da violência de gênero que contextualizamos anteriormente, privilegiando uma cobertura pontual e personificada. Nesse tipo de cobertura, o sentido político e estrutural da violência de gênero é deslocado e reduzido, na notícia jornalística, apenas ao sentido moral do caso de abuso sexual retratado, como expressa Segato, em entrevista concedida à Revista Ihu Online, publicada no portal do Instituto Humanitas Unisinos: "Não basta querermos somente consolar uma vítima que chora. O ponto é como educamos a sociedade para entender o problema da violência sexual como um problema político e não moral" (SEGATO, 2018).

Entendemos, assim, que a dimensão singular e individual e o tratamento descontextualizado dessas notícias desconsidera o potencial jornalístico de gerar entendimento e reflexão social sobre o fenômeno da desigualdade de gênero. Assim, ao apontar que as notícias enfatizam somente a "dor moral" da violência sofrida, Segato (2018) reitera ainda que essa narrativa "não deveria substituir, nem apagar ou se antepor à cena de uma mulher que se tornou uma agente política e por isso denuncia”.É constante a prática jornalística de retratar homens agressores e estupradores de maneira monstruosa e caricata, personificando uma figura descontrolada e psicótica. Tal como esclarece Segato, em entrevista publicada digitalmente, "esse monstro para outros homens resulta uma figura tentadora, porque o monstro é potente [...] como deve ser o sujeito masculino formatado pelo mandato da masculinidade" (SEGATO, 2018).

Na dissertação Estupro na imprensa: o processo de trabalho de jornalistas e profissionais de direito na cobertura do caso Roger Abdelmassih pelo jornal Folha de S.Paulo (2009-2015), na perspectiva de estudos de jornalismo, da legislação e das práticas do Poder, Malard Monteiro (2016) caracteriza o padrão da cobertura de violência sexual na imprensa tradicional brasileira, na análise dos assédios cometidos pelo médico Roger Abdelmassih. A partir da análise do caso na Folha de S.Paulo, Monteiro (2016) chama a atenção para a prática de "confinar a cobertura dos casos de estupro e violência sexual à vida pessoal das vítimas e agressores, sem revelar ou problematizar as características da desigualdade de gênero presentes neste tipo de crime" (MONTEIRO, 2016, p. 142). O estudo aponta que isso "resume um comportamento padrão da imprensa, que confina as violências de gênero ao ambiente doméstico, evitando que o problema seja percebido como uma questão de saúde pública” (MONTEIRO, 2019, p. 145). Ao destacar a dificuldade de apuração e comprovação dos assédios sexuais, a autora esclarece como essa problemática da violência sexual afeta a "busca pela verdade" no jornalismo. A ausência de provas materiais "alimenta no senso comum a ilusão de que mulheres inventam agressões sexuais por puro ‘desejo oculto”" (MONTEIRO, 2019, p.129). 


\section{A CENTRALIDADE MASCULINA COMO TRADIÇÃO DA CIÊNCIA E DO JORNALISMO}

Ao pensar as origens e razões da abordagem masculinista do jornalismo, conforme vimos até aqui, consideramos importante buscar as marcas e rastros dessa problemática na ciência tradicional, cujos princípios inspiram, historicamente, os modelos midiáticos. Neste entendimento, é inerente aferir que o gênero masculino é predominante na formação, na prática e no discurso jornalístico, assim como na ciência e demais campos de produção de conhecimento. É neste ponto, então, que alcançamos a epistemologia feminista como principal fonte teórica e conceitual para essa discussão. A partir da crítica ao "modo dominante de produção do conhecimento científico" (RAGO, 2019, p. 373), a epistemologia feminista surge como alternativa de criação de novos modelos científicos que englobem a experiência das mulheres.

Nesse sentido, reforçamos a ideia de que tal noção de conhecimento opera na sociedade a partir da exclusão da perspectiva feminina, assim como de outras perspectivas de raça e sexualidade, ao privilegiar a suposta universalidade masculina, enquanto representação legítima de produção do saber. Sendo o pensamento científico concentrado no "conceito universal" de "homem branco heterossexual civilizado do Primeiro Mundo" (RAGO, 2019, p. 374), é possível entender a maneira como o conhecimento tradicional exclui, marginaliza e estigmatiza quaisquer outras vivências e origens diferentes desse padrão masculino.

Dessa forma, a perspectiva feminista é apontada como um caminho possível para a construção da pluralidade e potencialidade da representação humana nas notícias. Deslocando seus discursos para distintos lugares de fala, inclusive o espaço da experiência feminina, que é historicamente deslegitimado dos relatos científicos, históricos e também jornalísticos, por ser tido como espaço privado, íntimo e subjetivo e, portanto, não digno da historicidade, representatividade e discussão social.

Assim sendo, a suposta posição de neutralidade, verdade eracionalidade defendida pela ciência tradicional se mostra contraditória e como uma espécie de representação específica da experiência masculina, uma vez que "os padrões de normatividade científica são impregnados por valores masculinos" (RAGO, 2019, p. 374). A partir dessa concepção, teorias feministas passam também a considerar, fundamentalmente, as determinações culturais que formam o conhecimento, os diferentes conceitos e significados que representam uma mesma realidade. Assim, a epistemologia feminista discute e propõe o rompimento do "padrão dualista" (p. 106) na ciência, como fundamenta Wilshire (1997), que gera a hierarquia entre noções de objetividade, mente, razão, frieza, ordem, linearidade, individualidade, factualidade - tidas como legítimas e associadas ao masculino - em detrimento e oposição a ideias associadas ao feminino, tais como subjetividade, corpo, emoção, intimidade, que são, portanto, deslegitimadas e não aceitas enquanto conhecimentos legítimos e verdadeiros.

Essas características "percebidas como não masculinas" foram, dessa forma, classificadas como "indignas" (WILSHIRE, 1997, p. 106), a partir do julgamento do patriarcado sobre o significado do que é ser feminino, que, no entanto, não corresponde ou engloba integralmente a experiência de homens e mulheres. Sendo assim, como defende Wilshire (1997), a legitimação desses aspectos ligados ao feminino, e tradicionalmente desqualificados como inferiores, subjetivos, privados e domésticos e até rotulados como ignorância, tabu e mitos, podem, a bem dizer, "intensificar e enriquecer a busca por verdade e conhecimento" (WILSHIRE, 1997, p. 106).

Com isso, tal visão feminista reivindica e constrói um entendimento de mundo que considera e potencializa a subjetividade feminina enquanto parte fundamental do conhecimento da realidade. Nesse processo, como descrito por Rago (2019), ao questionar a divisão corpo/mente, sentimento/razão, passamos a incorporar a "dimensão subjetiva, emotiva, intuitiva no processo do conhecimento" (RAGO, 2019, p. 380). Ressaltamos a necessidade de que as diversas formas de produção de conhecimento na sociedade, tal como o jornalismo, resgatem e façam emergir temas femininos tidos como íntimos e privados, mas que conectam a experiência 
feminina na história e nos fenômenos sociais. Nesse esforço, como também contextualiza Rago (2019), o feminismo e as lutas das mulheres têm trazido esses temas para a historicidade desde a década de 1970, inserindo no debate público questões como bruxaria, prostituição, aborto, parto, maternidade, sexualidade, emoções e sentimentos, levando à "visibilidade das mulheres como agentes históricos" (RAGO, 2019, p. 381).

Assim se dá a proposta de uma visão feminista do conhecimento (WILSHIRE, 1997), que promove a quebra desse padrão dualista, transcendendo essas polarizações para um entendimento integral da realidade, englobando relações complexas e complementares entre o feminino e o masculino, o subjetivo e objetivo, o público e o privado. Dessa maneira, a epistemologia feminista é definida como "uma forma de produção do conhecimento que traz a marca especificamente feminina, tendencialmente libertária e emancipadora" (RAGO, 2019, p. 319).

Tal como na ciência, o ideal de objetividade jornalística deslegitima a expressão da identidade feminina. O protocolo científico e midiático do discurso supostamente "neutro" abre caminho para privilegiar fontes e relatos masculinos, deslegitimando e considerando incorreto o uso de perspectivas femininas. Essa ausência de pluralidade reforça o sistema de valores, a produção simbólica e a construção cultural da estrutura patriarcal, privilegiando diversos discursos midiáticos, com abordagens, pontos de vista e maneiras de retratar a realidade que legitimam a desigualdade de gênero. Assim, entende-se que tais relatos de mulheres são excluídos a partir da lógica de que representam um desvio à objetividade, e, portanto, uma proximidade com a subjetividade, considerada inadequada na construção do conhecimento. Essa proposta se conecta com a proposta de alguns teóricos do jornalismo, no sentido de compreender o conhecimento como o resultado de condicionantes tanto objetivas quanto subjetivas, destacando, desse modo, sua dimensão, incontornavelmente, política:

[...] o conhecimento sobre a realidade histórico-social é sempre comprometido politicamente, pois ele se configura solidário em certas possibilidades do real e adversário de outras. Se o conhecimento das ciências naturais tende a expressar a objetividade, embora jamais consiga ser exaustivo, o conhecimento da sociedade converge para o momento de mútua criação entre a objetividade e a subjetividade, tendo a práxis como seu verdadeiro critério (GENRO FILHO, 1987, p. 212).

De acordo com Genro Filho (1987), a objetividade é um importante parâmetro que serve de meta para o jornalismo como forma de conhecimento, ou seja, é a fonte de toda a realidade. Entretanto, apesar de os fatos de interesse jornalísticos existirem independentemente dos jornalistas, o autor afirma que a notícia vai ser sempre o resultado de um recorte, de uma seleção de determinados aspectos, em detrimento de outros. Os fatos jornalísticos dependem, desse modo, de determinações tanto objetivas (que limitam o arbítrio dos sujeitos) quanto subjetivas (que viabilizam e produzem algum significado possível, frente ao caótico e múltiplo fluxo objetivo). Com efeito, a histórica opção pela tradicional visão do paradigma da objetividade, de inspiração positivista, revela, na realidade, uma opção política por entendimento específico da verdade.

Nessa discussão, Sponholz (2009) é outra autora que se afasta definitivamente da perspectiva construtivista radical, na medida em que aposta na possibilidade da correspondência entre o que se diz e o que, efetivamente, aconteceu. E de outro lado, Sponholz também se distancia da perspectiva do espelho, em que o sujeito do conhecimento consegue se anular completamente, desempenhando apenas a função neutra e imparcial de mediação entre a realidade e os cidadãos. "Neste sentido, o resultado de um processo de conhecimento não é nem espelhamento, nem invenção ou construção [totais], mas sim uma reconstrução da realidade (BENTELE, 1993, p. 160)" (SPONHOLZ, 2009, p. 19). Essa reconstrução não segue o arbítrio do sujeito, mas, de uma maneira ou de outra, precisa conar, fundamentalmente, com uma operação que só pode ser levada a cabo por ele: 
Como já discutido, a separação absoluta entre subjetividade e objetividade é não somente impossível, como também indesejável. Subjetividade e objetividade não são antônimos. Pelo contrário, subjetividade é uma condição para se alcançar objetividade (BENTELE, 1982, p. 131), assim como interesse uma condição para o conhecimento (SPONHOLZ, 2009, p. 28).

Ao desmistificar tais aspectos historicamente associados ao ideal de racionalidade humana, marcado pela tradição patriarcal, ressaltamos que as finalidades da objetividade e neutralidade foram impostas, no jornalismo, a partir dos princípios do iluminismo e positivismo, que são pilares da ciência moderna. Dessa forma, identificamos tal relação nos estudos de Josenildo Guerra (2008), que classifica "a influência dos princípios iluministas nas diferentes esferas da vida social moderna, sobretudo na ciência e na política" como uma das razões para o "peso do paradigma da objetividade no jornalismo". Assim, tais condições de valorização da razão, em detrimento das crenças e mitos, "vão ter desdobramentos tanto em relação às competências profissionais do jornalista quanto em relação à postura dos indivíduos que irão acolher o produto disponibilizado" (GUERRA, 2008, p. 137).

Esse entendimento do jornalismo como uma instituição social que surge, em meio à modernidade, para a orientação da vida é resultado de um entendimento funcionalista da instituição. Nessa perspectiva, a notícia se caracterizaria pela veracidade dos fatos, seria sistematizada como principal produto jornalístico, fabricada para circular socialmente e guiar cidadãos em torno de suas necessidades. Ao conceituar a notícia, Robert Park (2008), por exemplo, esclarece sua função de "orientar o homem e a sociedade num mundo real", no sentido de “"preservar a sanidade do indivíduo e a permanência na sociedade” (PARK, 2008, p. 69).

A limitação desse horizonte de compreensão da atividade jornalística é a premissa de que as notícias podem desempenhar para a sociedade, a mesma finalidade que a percepção cumpre para o indivíduo. Como argumenta Genro Filho (1987), apesar de o funcionalismo apontar o "caráter socializante" dos meios de comunicação em geral, as necessidades sociais e o jornalismo como forma de conhecimento, tal concepção carrega um "sentido vulgar e pragmático, vinculado apenas à reprodução da sociedade" (GENRO FILHO, 1987, p. 24).

O jornalismo, ao contrário, é uma atividade complexa, atravessada por múltiplas contradições, que realiza, não só uma ação de representação, como se fosse apenas lugar de mediação entre diversos segmentos e interesses sociais, mas, antes disso, opera como verdadeiro dispositivo de organização social. É nesse sentido que o caráter redutor dos relatos jornalísticos pode reforçar a desigualdade de gênero, com claras consequências de perpetuação da violência e da violação da vida de mulheres.

\section{A CONSTRUÇÃO DA NOTÍCIA COM PERSPECTIVA DE GÊNERO}

A partir dessas bases, direcionaremos nossas proposições para o entendimento da construção da notícia como um processo de apreensão dos fatos que engloba tanto subjetivações como a apuração precisa dos acontecimentos. Entendemos que esse processo envolve, inevitavelmente, a interpretação e reconstrução da realidade, na medida em que esta não se apresenta pronta e disposta a ser espelhada pelos meios de comunicação. As ocorrências apresentam diferentes perspectivas, interpretações e relações complexas, como também apontam os estudos da epistemologia feminista. Ao caracterizar a ideia tradicional da objetividade jornalística pela "compreensão do mundo como um agregado de 'fatos' prontos e acabados" (GENRO FILHO, 1987, p. 213), cuja existência seria independente de ideologias e concepções do mundo, Genro Filho (1987) denuncia o aspecto ingênuo dessa noção fundadora do jornalismo, que reduziria o papel do jornalismo à simples tarefa de recolher fatos prontos, "como se fossem pedrinhas coloridas" (GENRO FILHO, 1987, p. 213). Ao contrário desse entendimento, portanto, compreendemos a realidade enquanto 
fluxo desde o qual "os fatos são recortados e construídos obedecendo a determinações ao mesmo tempo objetivas e subjetivas” (GENRO FILHO, 1987, p. 213).

Ao desempenhar essa reconstrução da realidade, em um papel de significação que não só reflete, mas também produz verdade por meio da linguagem, conforme teorias da representação classificadas por Stuart Hall (2016), podemos entender que o jornalismo atua profundamente na produção simbólica e na significação do imaginário social. Assim a notícia constrói, discursivamente, o que significa o ser social em seus diferentes contextos. Neste fluxo de "reconstrução discursiva do mundo" (FRANCISCATO, 2005, p. 167), entendemos a apreensão das produções jornalísticas com um papel que, conforme argumenta Franciscato (2014), "oferece à sociedade formas específicas pelas quais indivíduo e sociedade produzem a sua vivência social do momento presente" (FRANCISCATO, 2014, p. 102).

De modo a captar toda a potencialidade dos fenômenos e ainda prevenir objetivismos e subjetivismos que possam distorcer a natureza dos fatos, consideramos parâmetros que estabeleçam um equilíbrio entre a correspondência precisa da notícia com a realidade e os aspectos subjetivos. Assim, nos fundamentamos ainda nos postulados de Gomes (2009), argumentando que "os fatos são sempre abertos, no sentido de que para existirem enquanto tal dependem da colaboração de um intérprete, continuam, de qualquer sorte, sendo fatos". E, portanto, sua natureza sugere que "podem suscitar infinitas interpretações, mas não consentem qualquer apreensão possível" (GOMES, 2009, p. 28). Dessa maneira, consideramos a necessidade da verificação jornalística enquanto meio de investigar a realidade, como se faz tão necessário no discernimento dos casos de assédios sexuais, abrangendo os elementos subjetivos como componentes fundamentais dessas realidades, mas não como qualquer interpretação, resultado de mero capricho subjetivo.

Depois desse esclarecimento, podemos conceituar a perspectiva de gênero na construção da notícia, como um processo que envolve, como ponto de partida, a compreensão da violência de gênero como uma classificação que potencializa a complexidade das relações sociais de gênero. A incorporação dessa perspectiva ao jornalismo se alia às demandas feministas, que historicamente apontam para a necessidade de discussão desse tipo de violência enquanto forma de enfrentamento desse problema, retirando essa questão da esfera da vida privada e familiar - onde se cultiva a dominação masculina e se aprisiona a experiência feminina - e o "legitimando como problema político e de saúde pública, envolvendo os direitos humanos das mulheres" (BANDEIRA, 2019, p. 298). Como defende a autora, essa crítica feminista abre caminho para "alterar parte dos equipamentos e serviços públicos, sem deixar de evidenciar as dificuldades de seu enfrentamento nas instituições públicas” (BANDEIRA, 2019, p. 299).

Diante das proposições alcançadas, torna-se fundamental considerar que a perspectiva de gênero no jornalismo corresponde à construção de discursos marcados pela pluralidade, que esclareçam a complexidade da realidade. Trata-se de uma empreitada que se relaciona não só com demandas e pautas feministas, mas reflete toda a necessidade de representar a potencialidade da experiência humana, tal como expressa Wilshire (1997): Muito do que faço pode ser chamado de 'valorização do feminino', mas estou realmente procurando tornar plena a experiência 'humana', resgatando o valor e o conhecimento no corpo 'humano', na emoção e no compartilhar humanos [...] (WILSHIRE, 1997, p. 106).

Reforçamos que o discurso jornalístico deve compreender a coexistência de diversos ideais de masculinidade, feminilidade, objetividade e subjetividade, mente e corpo, e assim por diante. Sem que haja, portanto, a necessidade de padrões normativos de separação e homogeneização entre tantos aspectos e expressões, paradoxais e complementares, que fazem parte da vivência social. 


\section{ANÁLISE DO LIVRO-REPORTAGEM ELA DISSE. REPORTANDO ASSÉDIOS SEXUAIS A PARTIR DA EXPERIÊNCIA FEMININA}

Em 2017, o debate sobre o assédio sexual contra mulheres tomou dimensões globais, com o movimento \#MeToo, uma hashtag nas mídias sociais conectou o mundo com relatos de abusos, muitos deles escondidos por anos e cometidos por homens públicos, com fama e poder, como descrevem Kantor e Twohey (2019):

Milhões de mulheres no mundo todo contaram suas próprias histórias de assédio. Muitos homens de repente tiveram de arcar com as consequências de seu comportamento predatório, em um momento de prestação de contas sem precedentes (KANTOR; TWOHEY, 2019, p. 5).

Essa transformação histórica "vinha sendo construída havia anos graças aos esforços pioneiros de feministas e acadêmicas" (KANTOR, TWOHEY, 2019, p. 5). Esse movimento foi impulsionado inclusive pelo jornalismo investigativo, com o papel fundamental das reportagens do NYT, ao narrar o contexto dos crimes sexuais e o respaldo social a esses atos de homens poderosos, como o produtor de Hollywood Harvey Weinstein, um dos principais acusados, que foi detido em meio às publicações, e o então presidente dos Estados Unidos, Donald Trump, entre outras figuras públicas. Como destacam as autoras das reportagens: "O jornalismo havia ajudado a inspirar uma mudança de paradigmas. Nosso trabalho foi apenas um dos catalisadores dessa mudança" (KANTOR, TWOHEY, 2019, p. 5).

Dois anos após o lançamento das primeiras reportagens, que repercutiram tanto no debate público, na punição de acusados, nas denúncias e na criação de novos setores e matérias jornalísticas sobre o tema, as mesmas autoras lançaram o livro Ela Disse: os bastidores da reportagem que impulsionou o \#MeToo (KANTOR, TWOHEY, 2019), revelando profundamente as práticas e os efeitos das reportagens assim como fornecendo mais detalhes da realidade da violência de gênero.

Os exemplos das repórteres do New York Times consolidam práticas de como o jornalismo pode atuar de forma sensível, profunda e humanizada. Esse seu trabalho perpassa ações da profissão como a apuração cuidadosa; os esforços de checagem de fatos, o cuidado com as vítimas e fontes em geral; e a investigação minuciosa de cada detalhe para uma contextualização ampla, segura e consistente dos abusos masculinos.

Nossa análise quer revelar aspectos concretos, além de escolhas e estratégias das repórteres, a partir dos seguintes critérios: 1) contextualização da violência de gênero e cultura do estupro como formas de organização social; 2) sensibilidade e subjetividade ao retratar a experiência feminina; 3) construção da notícia sobre assédio sexual, desafios de apuração e checagem; 4) perspectivas feministas de transformação social, que são propostas, esperadas e mobilizadas a partir das reportagens e suas repercussões.

Em primeiro lugar, classificamos certos trechos na categoria de contextualização da violência de gênero, selecionando as marcas discursivas que revelam a estrutura social de dominação masculina e violência contra mulheres. Tal critério vai ao encontro de estudos feministas que reforçam a necessidade da reflexão estrutural sobre a desigualdade de gênero, "ao questionar o ordenamento estruturador da ordem familiar e normatizador da sexualidade e dos corpos” (BANDEIRA, 2019, p. 298).

Como mostra o livro, as reportagens investigaram e descobriram um "padrão de comportamento predatório" (KANTOR, TWOHEY, 2019) em milhares de casos de assédios. Em indústrias cinematográficas e diversos campos profissionais, contra mulheres que iam de atrizes famosas a funcionárias e secretárias. Com isso as reportagens revelaram, essencialmente, parte do modus operandi da violência de gênero, tornando-se um importante registro histórico e de comportamento da sociedade.

Como ocorre em diversas reportagens investigativas, o surgimento de uma apuração em profundidade surge a partir do 'faro jornalístico' ao desconfiar e questionar uma lacuna social que demanda explicações. Assim também ocorreu com as repórteres do New York Times, sendo que suas curiosidades iniciais eram 
ainda mais escondidas e agravadas por envolverem o tabu do assédio sexual. Como revelam: "A investigação do New York Time sobre Harvey Weinstein começou sem que a fonte mais promissora aceitasse falar conosco, nem mesmo por telefone" (KANTOR; TWOHEY, 2019, p.11). Um dos primeiros indícios para a produção da reportagem surgiu de uma única denúncia identificada em um tweet, num momento em que não se previam as centenas de denúncias que viriam depois, a partir das reportagens. Diante do primeiro contato com a mulher que denunciava, a resposta foi resistente: "O problema é que já fui muito maltratada pelo seu jornal em algumas ocasiões, e acho que a causa foi o machismo [...] O NYT precisa prestar atenção no próprio machismo" (KANTOR; TWOHEY, 2019, p. 11-12), antecipando os desafios que as repórteres enfrentariam para gerar a quebra do silêncio das vítimas.

As repórteres foram, inicialmente, motivadas a questionar lacunas do contexto da violência sexual nos Estados Unidos: "O que faltava era mais exposição de fatos ocultos, em especial acerca do ambiente de trabalho” (KANTOR; TWOHEY, 2019, p. 16). A partir desse impulso inicial, a reportagem do NYT passa a girar em torno da tarefa das jornalistas de "ir além dos infratores individuais e definir os elementos e o sistema que faziam com que o assédio sexual continuasse a ser tão generalizado e difícil de abordar" (KANTOR; TWOHEY, p. 38, 2019). Tal como descrevem as autoras sobre suas experiências:

Ao escrever aquelas matérias, Jodi descobrira que gênero não era apenas uma pauta, mas uma espécie de porta de entrada investigativa. Como as mulheres ainda estavam à margem em muitas companhias, documentar o que elas vivenciavam mostrava como o poder funcionava (KANTOR, TWOHEY, p. 16, 2019).

Dessa maneira, percebemos o direcionamento da cobertura jornalística pela perspectiva de gênero, focado em investigar e retratar toda a complexidade desses padrões de comportamento. O livro revela que a busca desses padrões tornou-se um protocolo adotado, nesta e em diversas outras coberturas do NYT: "Quase nenhuma vítima se expunha se estivesse completamente sozinha. Mas se padrões de comportamento pudessem ser revelados, talvez houvesse uma maneira de contar mais histórias daquele tipo" (KANTOR, TWOHEY, 2019, p. 37).

Essa abordagem contextualizada conduziu o jornal a distribuir suas editorias entre diversas coberturas, focando principalmente em denunciar assédios sexuais sofridos por mulheres em diversas esferas públicas e do mundo do trabalho. Isso o levou a "averiguar diversas indústrias, como o Vale do Silício e a indústria de tecnologia, uma área utópica, supostamente livre das antigas regras, mas que ainda assim excluía as mulheres" (KANTOR, TWOHEY, 2019, p. 37). Com isso, o livro alcança ainda a retratação das tradições históricas e as permanências da desigualdade de gênero nos dias de hoje, numa realidade contemporânea de mulheres que conquistaram espaço no mercado de trabalho e na vida pública, como retratam:

[...] as mulheres tinham mais poder do que nunca. O número de empregos ocupados quase que exclusivamente por homens - policial, soldado, piloto de avião - tinha diminuído tanto que por pouco não se extinguiria. Mulheres governavam países como a Alemanha e o Reino Unido e lideravam empresas [...] Mas as mulheres continuavam a sofrer assédio sem que ninguém fosse punido (KANTOR, TWOHEY, 2019, p. 4).

Destacamos esse esforço jornalístico e feminista da cobertura do NYT, associando esse relato às reflexões de bell hooks (2019), que define a ascensão feminina ao mercado de trabalho como uma demanda do patriarcado capitalista moderno. Tal como contextualizou a autora: "Mais mulheres estão no mercado de trabalho dos Estados Unidos não como resultado do feminismo, mas porque famílias não conseguem mais contar com a renda do pai" (HOOKS, 2019, p. 173).

A busca de padrões de comportamento levou, então, à contextualização das reportagens sobre a estrutura de desigualdade de gênero dentro da organização da indústria cinematográfica de Hollywood. Elas declaram, 
então, que as apurações foram úteis para "ilustrar como o sistema jurídico e a cultura corporativa serviram para silenciar vítimas e ainda inibem a mudança. As empresas são cooptadas para proteger abusadoras” (KANTOR; TWOHEY, 2019, p. 7-8). Conforme apontam os estudos feministas, as instituições - como são neste caso as instituições da indústria do entretenimento estadunidense - operam de diversas maneiras para a manutenção do padrão de dominação masculina. São nessas organizações que "os princípios da perpetuação da dominação masculina são elaborados e impostos” (BANDEIRA, 2019, p. 304-305).

No caso da cobertura do NYT, o sistema de proteção do poder masculino se traduziu na maneira como as jornalistas identificam as estratégias e práticas que respaldam e mantêm esses crimes, muitas vezes sem representar qualquer ameaça às estruturas de poder dos homens que os cometem. Isso foi demonstrado com a revelação do sistema de indenizações financeiras que encobriam esses crimes. Ao longo das apurações, as reportagens revelaram o significado desse tipo de conduta: "tratava-se de uma prática-padrão para lidar com o assédio sexual. Muitas vezes, era a única maneira usada para lidar com o assunto" (KANTOR; TWOHEY, 2019, p. 76). Nos relatos, as jornalistas revelam as defesas dessas práticas pelos advogados, reforçando que, assim, as mulheres "podiam evitar o estigma de dedo-duro, mentirosa, mulher fácil ou pessoa que vivia processando todo mundo. Aquela era uma forma de receber uma indenização e tocar a vida” (KANTOR; TWOHEY, 2019, p. 76). Assim, tal entendimento levou Jodi Kantor a aferir que:

Os Estados Unidos tinham um sistema para silenciar queixas de assédio sexual que muitas vezes ajudava os assediadores a continuar com suas práticas em vez de impedi-los. Era comum que as mulheres assinassem um documento que tirava delas o direito de falar sobre suas próprias experiências. Os assediadores com frequência seguiam em frente, encontrando novos terrenos onde cometer os mesmos atos (KANTOR, TWOHEY, 2019, p. 76-77).

O livro expressa de maneira sensível a naturalização social de crimes tão brutais, que por serem banalizados e distanciados do debate público passam a ser normalizados, justamente pela falta de aproximação e escuta das vivências e dores das mulheres.

Não era novidade dizer que Hollywood se aproveitava das mulheres, forçava-as a ser submissas e as jogava fora quando envelheciam ou se rebelavam. Mas ouvir um relato de abuso em primeira mão de uma pessoa conhecida, com todos os detalhes perturbadores e envolvendo um dos produtores mais renomados de Hollywood como o assediador era bem diferente: mais agudo, mais específico, repugnante (KANTOR, TWOHEY, 2019, p. 19).

Esses esforços jornalísticos deram ainda mais impulsos às denúncias e aos debates à medida que questionaram o silenciamento das vítimas, incentivando a quebra do silêncio com ferramentas jornalísticas que garantiam proteção e representação das mulheres. A maioria delas silenciava os casos por anos, e já sofria com os efeitos psicológicos do silêncio, trauma e vergonha, havendo inclusive episódios de depressão e de tentativas de suicídio revelados no livro. Assim, o processo da reportagem de encorajar, libertar e empoderar essas mulheres foi transformador, visto que as repórteres as procuravam com cuidado e sensibilidade, e cada nova vítima que ia a público estimulava que outras se sentissem seguras, conquistando o legítimo direito à denúncia e à quebra de silêncio.

\section{CONCLUSÕES}

Diante do desafio de enfrentamento da violência contra mulheres, torna-se necessária a construção de memórias, historiografias, debates e discussões acerca da experiência feminina, pela urgência de refletir sobre a violência vivida por mulheres vítimas da dominação masculina. Como teoriza Rago (2019), entendemos que tais propostas de transformação social vão ao encontro da reinvenção de discursos, voltando-se para a representação de linguagens próprias da dimensão feminina: 
[...] se considerarmos que as mulheres trazem uma experiência histórica e cultural diferenciada da masculina, ao menos até o presente, uma experiência que várias já classificam como das margens, da construção miúda, da gestão do detalhe, que se expressa na busca de uma nova linguagem, ou na produção de um contradiscurso, é inegável que uma profunda mutação vem-se processando também na produção de conhecimento científico (RAGO, 2019, p. 373).

Assim sendo, argumentamos que essa valorização e reapropriação da vida das mulheres se dá pela construção e ampliação da epistemologia feminista, com a abertura crescente de espaços para que mulheres de diversas origens ocupem os discursos jornalísticos com suas próprias histórias e narrativas. Dessa forma, reforçamos a importância do jornalismo, conforme vimos na cobertura do NYT, que busca promover a ampliação dos olhares do conhecimento para a diversidade de vivências de mulheres.

\section{REFERÊNCIAS}

BANDEIRA, Lourdes Maria. Violência de gênero: a construção de um campo teórico e de investigação. In: HOLANDA, Heloisa Buarque de (org.). Pensamento feminista brasileiro: formação e contexto. Rio de Janeiro: Bazar do Tempo, 2019, p. 293-313.

BARDIN, Laurence. Análise de conteúdo. Tradução: Luís Antero Reto e Augusto Pinheiro. 4. ed. Lisboa: Edições 70, 2007.

FRANCISCATO, Carlos. O jornalismo e a reformulação da experiência do tempo nas sociedades ocidentais. Brazilian Journalism Research, Brasília, DF, v. 11, n. 2, p. 96-123, 2014. DOI: https://doi.org/10.25200/BJR. v10n2.2014.741. Disponível em: https://bjr.sbpjor.org.br/bjr/article/view/741. Acesso em: 11 jun. 2021.

FELIZARDO, Nayara; ALVES, Schirlei. 'As mordidas foram profundas': Curador brasileiro de festivais internacionais de cinema é acusado de abuso sexual por 16 mulheres. The Intercept Brasil, Rio de Janeiro, 28 ago. 2020. Disponível: https://theintercept.com/2020/08/28/curador-brasileiro-acusado-abuso-sexual/. Acesso em: 26 maio 2021.

FREIRE, Mariana. Campanha \#MeTooBrasil busca dar visibilidade aos relatos de violência sexual. Folha de S.Paulo. São Paulo, 2 set. 2020. Cotidiano. Disponível em: https://www1.folha.uol.com.br/cotidiano/2020/09/ campanha-metoobrasil-busca-dar-visibilidade-a-relatos-de-violencia-sexual.shtml. Acesso em: 26 maio 2021.

FÓRUM BRASILEIRO DE SEGURANÇA PÚBLICA. Visível e invisível: a vitimização de mulheres no Brasil. 2. ed. São Paulo: O Fórum, 2019. Disponível em https://forumseguranca.org.br/wp-content/uploads/2019/02/ relatorio-pesquisa-2019-v6.pdf. Acesso em: 28 jul. 2020.

GENRO FILHO, Adelmo. O segredo da pirâmide: para uma teoria marxista do jornalismo. Porto Alegre: Tchê, 1987.

GUERRA, Josenildo. O percurso interpretativo na produção da notícia: verdade e relevância como parâmetros de qualidade jornalística. São Cristóvão: Editora da UFS; Aracaju: Fundação Oviêdo Teixeira, 2008.

GOMES, Wilson. Jornalismo, fatos e interesses: ensaios de teoria do jornalismo. Florianópolis: Insular, 2009. (Série Jornalismo a rigor, v. 1).

HOOKS, Bell. E eu não sou uma mulher?: mulheres negras e feminismo. Tradução: Bhuvi Libanio. Rio de Janeiro: Rosa dos tempos, 2019.

HALL, Stuart. Cultura e representação. Rio de Janeiro: Ed. PUC-Rio: Apicuri, 2016.

KANTOR, Jodi; TWOHEY, Megan. Ela disse: os bastidores da reportagem que impulsionou o \#MeToo. Rio de Janeiro: Companhia das Letras, 2019.

MONTEIRO, Lieli Karine Vieira Loures Malard. Estupro na imprensa: o processo de trabalho de jornalistas e profissionais de direito na cobertura do caso Roger Abdelmassih pelo Jornal Folha de S.Paulo (2009-2015), na perspectiva de estudos de jornalismo, da legislação e das práticas do Poder. Orientação: Alice Mitika Koshiyama. 2016. 248 f. Dissertação (Mestrado em Ciências da Comunicação) - Escola de Comunicação e Artes, Universidade de São Paulo, São Paulo, 2016. 
PATEMAN, Carole. O contrato sexual. Rio de Janeiro: Paz e Terra, 1993.

PARK, Robert E. A notícia como forma de conhecimento: um capítulo da sociologia do conhecimento. Notícia e poder da imprensa. In: BERGER, Christa; MAROCCO, Beatriz. A era glacial do jornalismo. Porto Alegre: Sulina, 2008. v. 2. p. 51-70.

RAGO, Margareth. Epistemologia feminista, gênero e história. In: HOLANDA, Heloisa Buarque de (org.) Pensamento feminista brasileiro: formação e contexto. Rio de Janeiro: Bazar do Tempo, 2019. p. 371-387.

SAFFIOTI, Heleieth I. B. Contribuições feministas para o estudo da violência de gênero. Cadernos Pagu, Campinas, n.16, p.115-136, 2001. DOI: https://doi.org/10.1590/S0104-83332001000100007. Disponível em: https://www.scielo.br/j/cpa/a/gMVfxYcbKMSHnHNLrqwYhkL/?lang=pt. Acesso em: 11 jun. 2021.

SAFFIOTI, Heleieth I. B. Violência de Gênero no Brasil Atual. Estudos Feministas, Rio de Janeiro, n. especial, p. 443-461, 1994. Disponível em: https://periodicos.ufsc.br/index.php/ref/article/view/16177. Acesso em: 11 jun. 2021.

SEGATO, Rita. "O problema da violência sexual é político, não moral”: Entrevista com Rita Segato. [Entrevista concedida a] Marina Carbajal. Instituto Humanitas Unisinos, 2018. Disponível em: www.ihu.unisinos.br/78noticias/585609-o-problema-da-violencia-sexual-e-politico-nao-moral-entrevista-com-rita-segato. Acesso em: 20 maio 2021.

SPONHOLZ, Liriam. Jornalismo, conhecimento e objetividade: além do espelho e das construções. Florianópolis: Insular, 2009. (Série Jornalismo a rigor, v. 4).

WILSHIRE, Donna. Os usos do mito, da imagem e do corpo da mulher na re-imaginação do conhecimento. In: JAGGAR, Alison M., BORDO, Susan R. Gênero, corpo, conhecimento. Tradução: Britta Lemos de Freitas. Rio de Janeiro: Record: Rosas dos Tempos, 1997. p. 101-125. 